\title{
AlGaN/GaN High Electron Mobility Transistor Structure Design and Effects on Electrical Properties
}

E.L. Piner, D.M. Keogh ${ }^{\dagger}$, J.S. Flynn ${ }^{\dagger}$, and J.M Redwing ${ }^{\ddagger}$

Epitronics / ATMI, 21002 North $19^{\text {th }}$ Avenue, Suite 5, Phoenix, AZ 85027

${ }^{\dagger}$ ATMI Ventures / ATMI, 7 Commerce Drive, Danbury, CT 06810

${ }^{\ddagger}$ Current Address: Penn State University, Dept. of Materials Science and Engineering, University Park, PA 16802

\begin{abstract}
We report on the effect of strain induced polarization fields in $\mathrm{AlGaN} / \mathrm{GaN}$ heterostructures due to the incorporation of Si dopant ions in the lattice. By Si-doping $(\mathrm{Al}) \mathrm{GaN}$, a contraction of the wurtzite unit cell can occur leading to strain in doped $\mathrm{AlGaN} / \mathrm{GaN}$ heterostructures such as high electron mobility transistors (HEMTs). In a typical modulation doped AlGaN/GaN HEMT structure, the Si-doped AlGaN supply layer is separated from the two-dimensional electron gas channel by an undoped AlGaN spacer layer. This dopant-induced strain, which is tensile, can create an additional source of charge at the AlGaN:Si/AlGaN interface. The magnitude of this strain increases as the $\mathrm{Si}$ doping concentration increases and the AlN mole fraction in the AlGaN decreases. Consideration of this strain should be given in AlGaN/GaN HEMT structure design.
\end{abstract}

\section{INTRODUCTION}

Strain induced piezoelectric polarization is a critical factor in the creation of the twodimensional electron gas (2DEG) at the strained $\mathrm{AlGaN} /$ relaxed $\mathrm{GaN}$ interface in a high electron mobility transistor (HEMT) structure ${ }^{1,2}$. This strain is a result of the lattice mismatch between $\mathrm{Al}_{\mathrm{x}} \mathrm{Ga}_{1-\mathrm{x}} \mathrm{N}$ and $\mathrm{GaN}$ ( $\mathrm{x}$ is typically between 0.15 and 0.30 ). To further enhance the sheet carrier concentration of the 2DEG, a Si-doped AlGaN layer may be grown that is typically separated from the channel by an undoped AlGaN spacer layer. An additional $1 \mathrm{E} 13 \mathrm{~cm}^{-2}$ sheet density of carriers can be obtained by doping the AlGaN at $0.5-5 \mathrm{E} 19 \mathrm{~cm}^{-3} \mathrm{Si}$. This is about a factor of two increase over an undoped $\mathrm{AlGaN} / \mathrm{GaN}$ HEMT structure.

By doping with $\mathrm{Si}$, a perturbation of the lattice occurs due to the substitution of the smaller Si ion on the column III lattice site. This creates an additional contraction of the $\mathrm{AlGaN}$ wurtzite unit cell thus creating strain at the AlGaN:Si donor layer / AlGaN spacer layer interface. A similar effect in bulk GaN:Si epilayers grown on sapphire has been observed. ${ }^{3}$ However, in this case, the effect of the strain from the Si-dopant was a source for stress relaxation due to the inherent compressive strain associated with $\mathrm{GaN}$-onsapphire caused by the differences in lattice constant, as well as, thermal coefficients of expansion between $\mathrm{GaN}$ and $\alpha$-sapphire. A determination of the strain associated with incorporating $\mathrm{Si}$ as a substitutional dopant and the effects on the HEMT structure design are discussed. 


\section{EXPERIMENTAL}

For an $\mathrm{Al}_{\mathrm{x}} \mathrm{Ga}_{1-\mathrm{x}} \mathrm{N}$ :Si layer pseudomorphically strained on a relaxed $\mathrm{Al}_{\mathrm{x}} \mathrm{Ga}_{1-\mathrm{x}} \mathrm{N}$ layer, the strain, $\varepsilon_{\perp}$, is given by,

$$
\mathcal{E}_{\perp}=2 x_{A l}\left(\frac{a_{(A l) G a N}}{a_{(A l) G a N: S i}}-1\right)
$$

where $\mathrm{a}_{(\mathrm{Al}) \mathrm{GaN}}$ is the a-axis lattice constant for $\mathrm{AlN}$ content in the range of $0-100 \%$. Vegard's Law of linear interpolation is assumed. $\mathrm{a}_{(\mathrm{Al}) \mathrm{GaN}: \mathrm{Si}}$ is the corresponding a-axis lattice constant at a given Si doping concentration. Table 1 summarizes the lattice constants as a function of Si-doping for GaN:Si and AlN:Si determined by substituting the atomic percent $\mathrm{Si}$ associated with the doping level for $\mathrm{Ga}$ and/or $\mathrm{Al}$ on the column III lattice site of the wurtzite unit cell. $100 \%$ activation of the Si dopant was assumed. The undoped GaN and AlN a-axis lattice constants were taken to be 3.1892 and 3.112A, respectively. ${ }^{4}$

Additional calculations were performed to determine the strain associated with AlGaN on a relaxed $\mathrm{GaN}$ layer. The equation for strain, in this case, would be,

$$
\varepsilon_{\perp}=2 x_{A l}\left(\frac{a_{G a N}}{a_{A l N}}-1\right) \cong 0.0495 x_{A l},
$$

where $\mathrm{a}_{\mathrm{GaN}}$ and $\mathrm{a}_{\mathrm{AIN}}$ are the a-axis lattice constants that were defined earlier and $\mathrm{x}$ is the AlN mole fraction which ranges from $0-1$. No relaxation of the $\mathrm{AlGaN}$ or $\mathrm{AlGaN}: \mathrm{Si}$ was assumed. This would be the case for AlGaN layers below the critical thickness for relaxation.

\section{RESULTS}

Figure 1 illustrates the strain associated with doping $\mathrm{Al}_{\mathrm{x}} \mathrm{Ga}_{1-\mathrm{x}} \mathrm{N}$ with $\mathrm{Si}$ for doping concentrations of $5 \mathrm{E} 18,1 \mathrm{E} 19$, and $5 \mathrm{E} 19 \mathrm{~cm}^{-3}$ and as a function of the $\mathrm{Al}$ content $(0 \leq \mathrm{x} \leq 1)$. As would be expected, the strain is a strong function of the Si-doping concentration and increases with increasing doping. It should be noted that this strain is tensile since the $\mathrm{Si}$ dopant creates a smaller unit cell compared to the equivalent $\mathrm{Al}$ mole fraction $\mathrm{Al}_{\mathrm{x}} \mathrm{Ga}_{1-\mathrm{x}} \mathrm{N}$

Table 1. Lattice constants (a-axis) determined for GaN and AlN at Si-doping concentrations of $5 \mathrm{E} 18,1 \mathrm{E} 19$, and $5 \mathrm{E} 19 \mathrm{~cm}^{-3}$.

\begin{tabular}{|c|c|c|}
\hline $\begin{array}{c}\text { Si-doping conc. } \\
\left(\mathrm{cm}^{-3}\right)\end{array}$ & GaN:Si & AlN:Si \\
\hline $5 \mathrm{E} 18$ & 3.1891 & 3.1119 \\
\hline $1 \mathrm{E} 19$ & 3.1890 & 3.1117 \\
\hline $5 \mathrm{E} 19$ & 3.1882 & 3.1111 \\
\hline
\end{tabular}




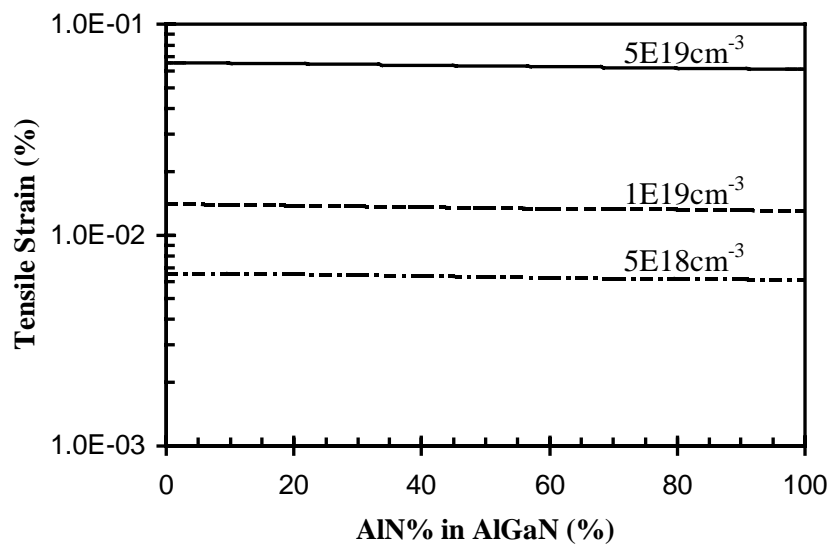

Figure 1. Si-doping induced strain as a function of mole fraction AlN in AlGaN. Si doping levels are as noted on the graph.

undoped unit cell. (This strain is similar in nature to adding additional $\mathrm{Al}$ to an undoped $\mathrm{AlGaN}$ in, for instance, an AlGaN/GaN HEMT structure.)

Figure 1 also indicates a slight decrease in the strain as the AlN mole fraction increases. This is a result of the AlN unit cell being smaller than the GaN unit cell and, thus, the $\mathrm{Si}$ substitutional impurity has less of an effect on the AlN lattice compared to the GaN lattice. The Si-doping strain increases with: 1. Increasing Si concentration and 2. Reducing AlN content of the AlGaN. The strain associated with doping GaN with $5 \mathrm{E} 19 \mathrm{~cm}^{-3} \mathrm{Si}$ is $0.066 \%$ and is tensile.

\section{DISCUSSION}

Of greater interest to HEMT structure design is how this effect manifests itself in a strained $\mathrm{AlGaN} /$ relaxed $\mathrm{GaN}$ system. Figure 2 is a graph of the strain associated with pseudomorphically strained $\mathrm{AlGaN}$ on relaxed $\mathrm{GaN}$. If the $\mathrm{AlGaN}$ is doped with $\mathrm{Si}$, the effect of the pseudomorphic and doping-induced strain is cumulative and increases the overall strain as shown by the dashed line of figure 2. The strain from incorporating $5 \mathrm{E} 19 \mathrm{~cm}^{-3} \mathrm{Si}$ into the lattice is equivalent to increasing the AlN content in AlGaN by $\sim 1.4 \%$. As the Si-doping level decreases, the dashed line would move closer to the solid line and the doping-induced strain would decrease as shown in figure 1.

In a modulation doped $\mathrm{AlGaN} / \mathrm{GaN}$ HEMT, it is common practice to incorporate a thin undoped $\mathrm{AlGaN}$ spacer layer between the GaN and $\mathrm{AlGaN}$ :Si to spatially remove the ionized donors from the channel. The resulting structure is schematically shown in figure 3. A Ga-faced crystal structure is assumed which is the common polarity in metalorganic chemical vapor phase epitaxially grown $\mathrm{GaN} .^{5}$ However, a similar argument could be made for a $\mathrm{N}$-faced crystal. 


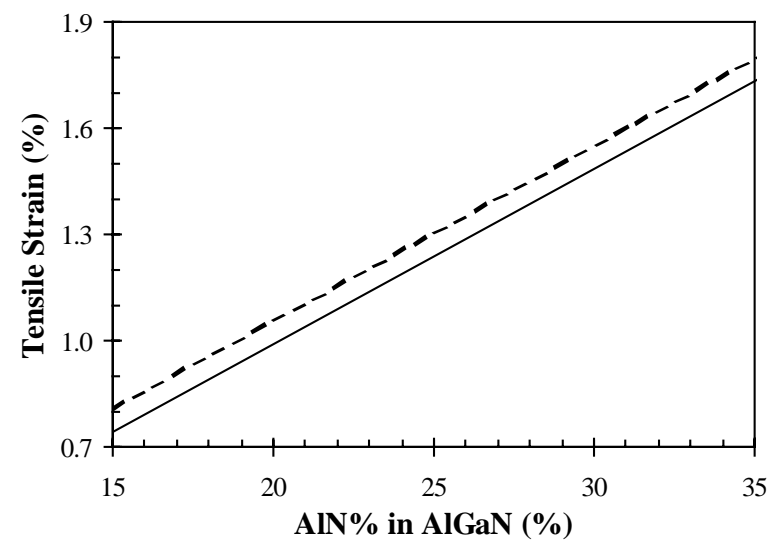

Figure 2. Calculated strain for undoped AlGaN (solid line) and AlGaN:Si at a doping concentration of $5 \mathrm{E} 19 \mathrm{~cm}^{-3}$ (dashed line).

Figure 3 indicates the formation of the $2 \mathrm{DEG}$ at the $\mathrm{AlGaN}$ spacer layer / relaxed $\mathrm{GaN}$ layer interface. The sheet carrier concentration of the $2 \mathrm{DEG}$ depends on both the spontaneous and piezoelectric polarization associated with the $\mathrm{AlGaN} / \mathrm{GaN}$ heterostructure. The additional lattice mismatch associated with the Si-doping will result in a second source of strain localized at the $\mathrm{AlGaN}$ :Si donor layer / AlGaN spacer layer interface. This strain manifests itself by the creation of an additional piezoelectric polarization in the AlGaN:Si donor layer. Due to the tensile nature of this strain, the resulting sheet charge will be positive. This additional sheet charge may accumulate at the $\mathrm{AlGaN}: \mathrm{Si} / \mathrm{AlGaN}$ interface resulting in a second $2 \mathrm{DEG}$ channel. The piezoelectric polarization associated with $5 \mathrm{E} 19 \mathrm{~cm}^{-3} \mathrm{Si}$ is $\sim 0.35 \mathrm{E} 12 \mathrm{~cm}^{-2}$ which is an additional $1-4 \%$ of the polarization induce sheet charge generated by the $\mathrm{Al}_{\mathrm{x}} \mathrm{Ga}_{1-\mathrm{x}} \mathrm{N} / \mathrm{GaN}$ heterostructure ( $\mathrm{x}$ is in the range of $0.15-0.35$ ).

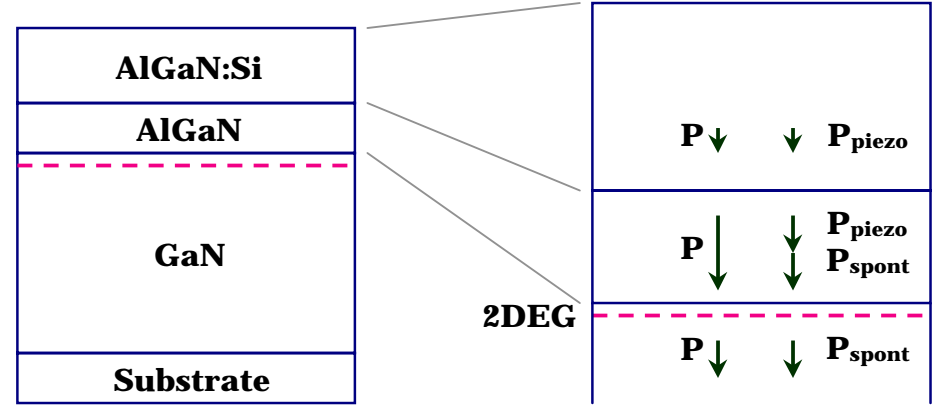

(a)

(b)

Figure 3. (a) modulation doped AlGaN/GaN HEMT structure and (b) the corresponding polarization fields. (Ga-faced crystal is assumed.) 


\section{CONCLUSIONS}

Si-doping $(\mathrm{Al}) \mathrm{GaN}$ causes a contraction of the wurtzite unit cell and can be a source of strain in doped $\mathrm{AlGaN} / \mathrm{GaN}$ heterostructures. In a modulation doped $\mathrm{AlGaN} / \mathrm{GaN}$ HEMT structure, in which the Si-doped AlGaN supply layer is separated from the 2DEG channel by an undoped $\mathrm{AlGaN}$ spacer layer, dopant-induced strain can create an additional source of charge at the AlGaN:Si/AlGaN interface. The magnitude of this strain increases as the Si doping concentration increases and the AIN mole fraction in the AlGaN decreases. The effect on the strain due to adding additional Si has a much greater effect than reducing the $\mathrm{Al}$ content in the $\mathrm{AlGaN}$. Consideration of this strain should be given in AlGaN/GaN HEMT structure design.

\section{ACKNOWLEDGMENTS}

Support for this research was provided by the U.S. Army Ballistic Missile Defense Organization and the Air Force.

\section{REFERENCES}

1. P.M. Asbeck, E.T. Yu, S.S. Lau, G.J. Sullivan, J. Van Hove, and J.M. Redwing, Electron. Lett. 33, 1230 (1997).

2. E.T. Yu, G.J. Sullivan, P.M. Asbeck, C.D. Wang, D. Qiao, and S.S. Lau, Appl. Phys. Lett. 71, 2794 (1997)

3. C.S. Kim, D-K Lee, C-R Lee, S.K. Noh, I-H Lee, and I-H Bae, Mater. Res. Soc. Symp. Proc. 482, 567 (1998).

4. Properties of Group III Nitrides, edited by J.H. Edgar (INSPEC, London, 1994).

5. O. Ambacher, J. Smart, J.R. Shealy, N.G. Weimann, K. Chu, M. Murhpy, W.J. Schaff, L.F. Eastman, R. Dimitrov, L. Wittmer, M. Stutzmann, W. Rieger, and J. Hilsenbeck, J. Appl. Phys. 85, 3222 (1999). 